\title{
LEXICOGRAPHY AND GENERATIVE GRAMMAR I: HEDGES AND MEANING CRITERIA *
}

\author{
George Lakoff $\dagger$ \\ Department of Linguistics \\ University of Michigan \\ Ann Arbor, Michigan 48108
}

Lexicography is an art-and one where practical considerations outweigh scientific considerations. Linguistics has discovered a great many new facts about words in recent years, but this does not necessarily mean that such facts can or even should be included in any dictionary no matter what its degree of abridgement. In fact, including technical linguistic discoveries in a dictionary may be the last thing a good lexicographer would want to do. On the other hand, technical linguistic dişcoveries, if used as a very subservient handmaiden to lexicographic craft, could conceivably lead to better dictionaries. What I would like to do is report on some linguistic discoveries, knowing that they cannot and should not be directly applied to the making of dictionaries, but nonetheless hoping that some lexicographers will find a way to make practical use of them.

As any lexicographer knows, natural language. concepts are fuzzy; the boundaries are not clear-cut. Zadeh has suggested that fuzziness should be handleable formally in terms of what he calls fuzzy set theory. ${ }^{1}$ In a fuzzy set, an individual is not simply a member or a non-member, but may be a member to some degree, for example, any real number between 0 and 1. Take the fuzzy concept of tallness. Someone who is $6^{\prime} 5^{\prime \prime}$ is clearly tall, and someone who is $5^{\prime} 0^{\prime \prime}$ is clearly not tall. But what about someone who is $5^{\prime} 7^{\prime \prime}, 5^{\prime} 9^{\prime \prime}, 5^{\prime} 11^{\prime \prime}$ ? Zadeh suggests that such individuals exhibit intermediate degrees of tallness. Obviously, as one's height becomes greater, so one's degree of tallness becomes greater-until a certain threshold is reached. Zadeh has suggested that concepts such as tall are to be represented graphically, pretty much as in FIGURE 1. Interestingly enough, there are words that change fuzziness. Consider, for example, the expression "sort of." The concept "sort of tall," if represented graphically, would look approximately as in Figure 2. Clearly, if someone is $6^{\prime} 5^{\prime \prime}$, he is not sort of tall-he is just plain tall. But if you are, say, $5^{\prime} 9^{\prime \prime}$, then you are sort of tall. Essentially, the expression "sort of" raises the intermediate values and lowers the high values for "tall." One might think that tallness is a rather special case. After all, tallness can be described as a continuous function of height plus various contextual factors. But what about more "discrete" concepts? Take the concept of a bird. Heider," in a psychological experiment, has shown that people do not perceive birdiness as a yes-or-no affair. Rather there seem to be gradations of birdiness. A hierarchy like that given in (1) emerged from her studies.

* This work was partially supported by grant NSF-2939 from the National Science Foundation to the University of Michigan. It was written while the author was in residence at the Center for Advanced Study in the Behavioral Sciences, Stanford, Calif.

$\dagger$ Present address: University of California, Berkeley, Calif. 94720. 


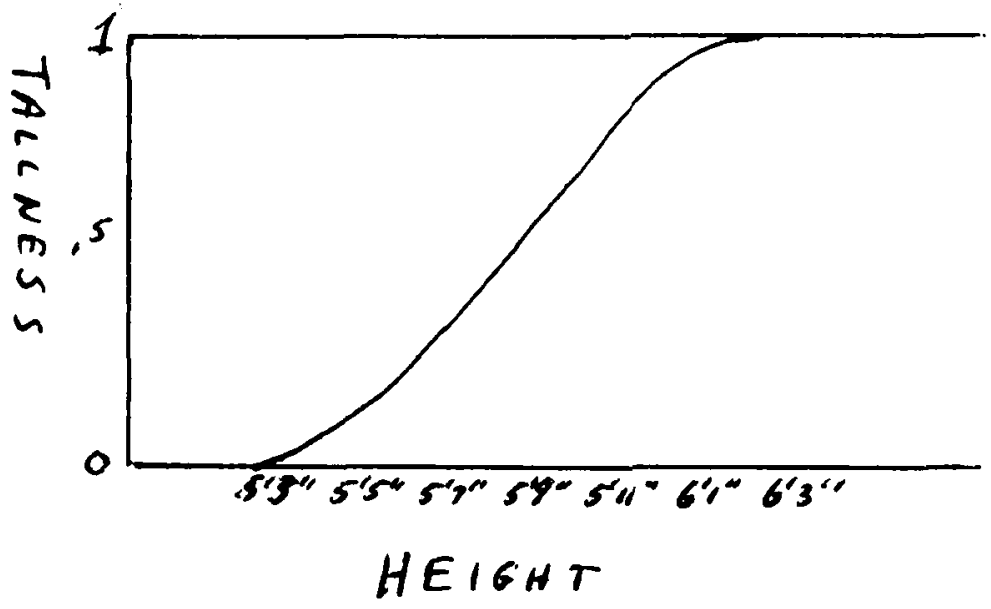

Figure 1

(1) Birdiness hierarchy robins, sparrows chickens, ducks, geese penguins, pelicans bats

A robin is more typical of a bird than a chicken and a chicken is more typical of a bird than a penguin. Bats have a very small degree of birdiness, and cows none at all. We can represent these results graphically with discrete points as in FIGURE 3. Corresponding sentences in (2) show, of course, a corresponding degree of truth.

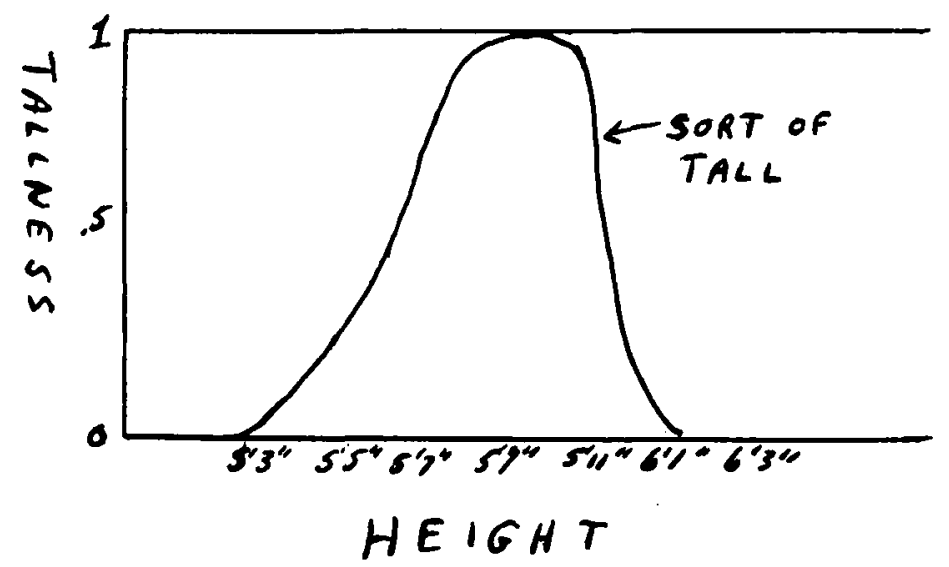

Figure 2 


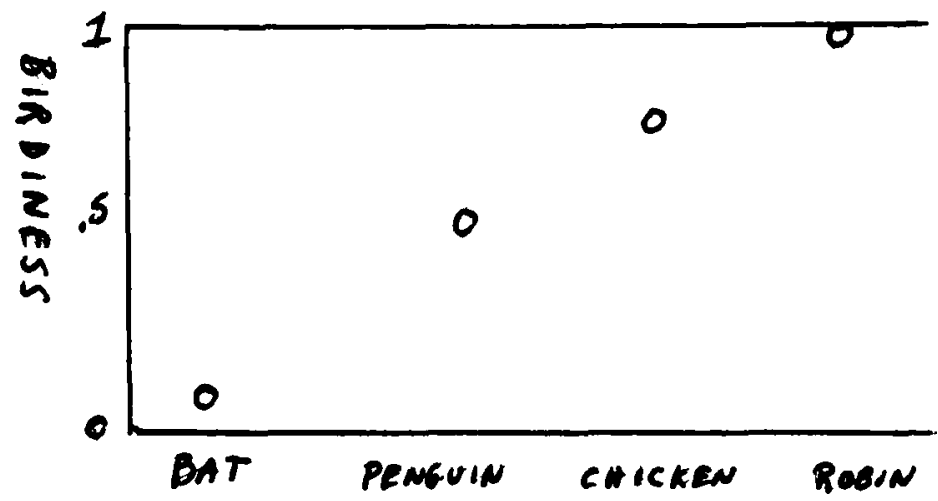

Figure 3

(2) Degree of truth (corresponding to degree of category membership)
a. A robin is a bird.
b. A chicken is a bird.
c. A penguin is a bird.
d. A bat is a bird.
e. A cow is a bird.

(true)

(less true than a)

(less true than $b$ )

(false, or at least very far from true)

(absolutely false)

Now suppose that bird is modified by "sort of." Consider sentences in (3).

(3) a. A robin is sort of a bird.

(False-it is a bird, no question about it)

b. A chicken is sort of a bird. (True, or very close to true)

c. A penguin is sort of a bird. (True, or close to true)

d. A bat is a sort of a bird. (Still pretty close to false)

e. A cow is a sort of a bird. (False)

What one gets is, graphically, the graph of FIGURE 4 . If one fills in the line to

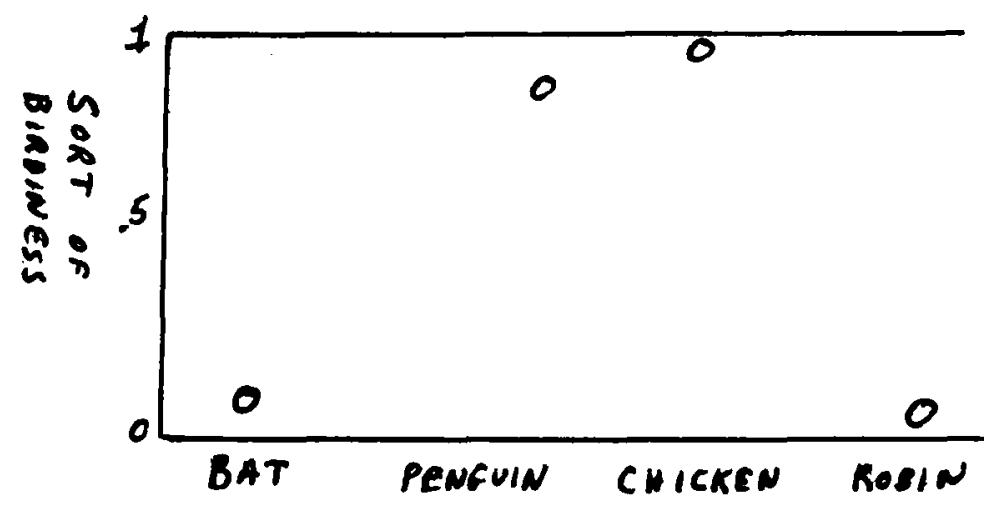

FIGURE 4 
form a continuous curve, one can see that the effect of "sort of" on degrees of birdiness is very much like the effect of "sort of" on the concept of tallness.

I have referred to words like "sort of" as "hedges." A small and relatively random list is given on the following page. What I would like to suggest is that study of hedges reveals a great deal about meaning that is not obvious. Hedges do not merely reveal distinctions of degree of category membership. They can also reveal a great deal more structural information. Consider (4).

(4) a. Esther Williams is a fish.

b. Esther Williams is a regular fish.

(4a) is false, since Esther Williams is a human being, not a fish. (4b), on the other hand, would seem to be true, since it says that Esther Williams swims well and is at home in water. Note that (4b) does not assert that Esther Williams has gills, scales, fins, a tail, etc. In fact, (4b) presupposes that Esther Williams is not literally a fish and asserts that she has certain other characteristic properties of a fish. Bolinger (in press) has suggested that regular picks out certain "metaphorical" properties. We can see what this means in an example like (5).

(5) a. John is a bachelor.

b. John is a regular bachelor.

(5b) would not be said of a bachelor. It might be said of a married man who acts like a bachelor-dates a lot, feels unbound by marital responsibilities, etc. In short, regular seems to assert the connotations of "bachelor," while presupposing the negation of the literal meaning. (6) reveals the same fact, though perhaps more clearly.

(6) a. Sarah is a spinster.

b. Sarah is a regular spinster.

(6) asserts that Sarah has certain characteristics properties of spinsterspresumably that she is prissy and disdains sexual activity. (6b) would not be said of someone who was literally a spinster, but might be said either of a married woman or a girl who was not yet past marriageable age who acted like a spinster. What (6b) asserts is the connotation of "spinster"-prissiness and lack of sexual activity, while presupposing the negation of the literal meaning.

If this account of the meaning of regular is essentially correct, a rather important conclusion follows. It is usually assumed that the connotations of words are part of pragmatics - the wastebasket of the study of meaning. Certainly most philosophers seem to take it for granted that connotations and other pragmatic aspects of meaning are irrelevant to the assignment of truth values (leaving aside sentences containing indexical expressions). Truth is usually taken to involve literal or denotative meaning alone. Yet in sentences with regular, such as (4b), (5b) and (6b), the truth value of the sentences as a whole depends not upon the literal meaning of the predicates involved, but strictly upon their connotations! What this indicates, I think, is that semantics cannot be taken to be independent of pragmatics, but the two are inextricably tied together.

In the above discussion I used the terms "literal meaning" and "connotation" as though they were adequate to describe at least informally the types of 
Some Hedges and Related Phenomena

sort of

kind of

loosely speaking

more or less

on the — side (tall, fat, etc.)

roughly

pretty (much)

relatively

somewhat

rather

mostly

technically

strictly speaking

essentially

in essence

basically

principally

particularly

par excellence

largely

for the most part

very

especially

exceptionally

quintessential(ly)

literally

often

more of a - than anything else

almost

typically/typical

almost

as it were

in a sense

nearly

in one sense

commonly

typically in a real sense

in an important sense

in a way

mutatis mutandis

in a manner of speaking

details aside

so to say

a veritable

a true

a real

a regular

virtually

all but technically

practically

all but a

anything but a

a self-styled

nominally

he calls himself a ...

in name only

actually

really

(he) as much as . . .

-like

-ish

can be looked upon as

can be viewed as

pseudo-

crypto-

(he's) another (Caruso/

Lincoln/Babe Ruth . . .)

- is the - of -

(e.g., America is the

Roman Empire of the modern world.

Chomsky is the

DeGaulle of

Linguistics, etc.) 
meaning components affected by hedges and related words. But as might be expected the situation is more complex. We can see this if we try to find some hedges that are opposites of regular, ones which pick out literal meaning alone. Two promising candidates are strictly speaking and technically.

(7) a. A whale is technically a mammal.

b. Strictly speaking a whale is a mammal.

Technically and strictly speaking seem to have the same effect in (7a) and (b). However, in other sentences they produce radically different results.

(8) a. Richard Nixon is technically a Quaker. (true)

b. Strictly speaking, Richard Nixon is a Quaker. (false)

(9) a. Ronald Reagan is technically a cattle rancher. (true)

b. Strictly speaking, Ronald Reagan is a cattle rancher. (false)

As (8) and (9) show, technically picks out some definitional criterion, while strictly speaking requires both the definitional criterion and other important criteria as well. Richard Nixon may be a Quaker in some definitional sense, but he does not have the religious and ethical views characteristic of Quakers. He meets the definitional criterion, but not other important criteria. Ronald Reagan meets a definitional criterion for being a cattle rancher, since he happens to have bought cattle stocks as a tax dodge (which is how he avoided 1970 income taxes). However, he does not meet all of the primary criteria for being a cattle rancher.

(10) a. Strictly speaking, George Wallace is a racist.

b. Technically, George Wallace is a racist.

Note that, as (10) shows, technically seem to mean only technically, that is it asserts that the definitional criteria are met but that some important criterion for category membership is not met. Hence the strangeness of (10b).

Strictly speaking contrasts interestingly with loosely speaking.

(11) a. Strictly speaking, a whale is a mammal.

b. Loosely speaking, a whale is a fish.

(11) shows the need for distinguishing between important or primary properties on the one hand and secondary properties on the other hand. (11a) says that whales classify as mammals if we take into account important criteria for distinguishing mammals from fish. For example, they give live birth and breathe air. (11b) seems to say that we can classify whales as fish if we ignore the primary properties and take into account certain secondary properties, for example, their general appearance and the fact that they live in water. Thus, we need to distinguish between primary and secondary criteria for category membership.

However, loosely speaking still differs sharply from regular, as the following examples show:

(12) a. Harry is a regular fish.

b. Loosely speaking, Harry is a fish.

(13) a. Loosely speaking, a whale is a fish.

b. A whale is a regular fish. 
What is strange about $(12 b)$ is that it asserts that Harry is a member of the category fish to some degree by virtue of having some secondary property of fish. (12a) simply says that he swims well and is at home in water, while it presupposes that he is not a member of the category fish to any degree whatsoever. The distinction between (12a) and (12b) indicates that we must distinguish between those properties capable of conferring some degree of category membership and those properties which happen to be characteristic of category members, but do not confer category membership to any degree at all. No matter how well you swim, that won't make you a fish to any degree at all. But if you are a living being, live in the water, are shaped like a fish, and your only limbs are flippers and a tail, it would seem that, like the whale, you are, loosely speaking, that is by virtue of secondary criteria, a member of the category fish to some extent. Note that (13b) is odd in that it presupposes that the whale is not a member of the category fish to any extent.

An adequate account of the functioning of characteristic-though-incidental properties should provide an understanding of at least one type of metaphor. Suppose I say "John is a fish." I am using a metaphor to indicate either that he swims well or that he is slimy (in the nonliteral sense). The mechanism for this is, I think, something like the following. Since it is presupposed that the subject, John, is not literally a member of the category fish, one cannot be asserting membership in that category if the sentence is to make sense. Instead, the sentence is understood in essentially the same way as "John is a regular fish," that is, the contextually most important incidental-though-characteristic properties are asserted.

By looking at just four hedges-technically, strictly speaking, loosely speaking and regular-we have seen that we must distinguish at least four types of criteria for category membership:

(14) Types of Criteria

1. Definitional

2. Primary

3. Secondary

4. Characteristics though incidental-not capable of conferring category membership to any degree, but contributes to degree of category membership if some degree of membership is otherwise established.

These distinctions are necessary for even a primitive account of how such hedges function. Such a primitive account is given in (15).

(15) An Informal and Inadequate Approximation to an Understanding of Some Hedges

TECHNICALLY - Truth value depends upon values of definitional criteria alone. Implies that at least one primary criterion is below the threshold value for simple category membership.

STRICTLY SPEAKING-Truth value depends on value of definitional and primary criteria. Values for each criterion must be above certain threshold values. 
LOOSELY SPEAKING-Truth value depends primarily on secondary criteria. Implies that threshold values for definitional and primary criteria are insufficient to confer category membership.

REGULAR-Truth value depends upon characteristic-though-incidental criteria. It is presupposed that the values of other criteria are insufficient to establish any degree of category membership.

There are two points to be made here for lexicography. First, there are words like "sort of" and "regular" whose meaning can only be given by the way they affect the meanings of other words. This is true of hedges in general. Secondly, hedges reveal that there is a structure to meaning criteria; and such structure is rarely revealed in dictionary definitions. To take an example, consider the following entry for "fish" in the Random House Dictionary of the English Language.

(16) 1. Any of various cold-blooded, completely aquatic vertebrates, having gills, commonly fins, and typically an elongated body usually covered with scales.

2. Any of various other aquatic animals.

(Note the use of hedges "typically," "commonly," and "usually" in the definition of 1.)

As the study of hedges reveals, these are not two separate, distinct meanings for the word "fish." Rather they arise out of the hierarchical structure of meaning criteria. In contexts where the term is used loosely, one gets the second reading, while in contexts where the term is used strictly, one gets the first. When it comes to the meaning criteria picked out by the hedge "regular," dictionaries are often of little or no help. Consider the following entries in the definitions for "bachelor," "spinster," and "lawyer" in the Random House dictionary.

(17) Bachelor: 1. An unmarried man.

Spinster: 1. A woman still unmarried beyond the usual age of marrying; an old maid. 2. Chiefly law. A woman who has never married.

Lawyer: 1. A person whose profession is to conduct lawsuits for citizens in a court of law and to advise or act for clients in other legal matters.

There is no way that, say, a non-speaker of English could, looking at these dictionary definitions, figure out what the following sentences mean.

(18) a. He is a regular bachelor.

b. She is a regular spinster.

c. He is a regular lawyer.

The reason is that dictionaries don't usually include connotational information. The Random House entry for "politician" is more helpful.

(18) Politician-1. A person who is active in party politics. 2. A seeker 
or holder of public office who is more concerned about winning favor or retaining power than about maintaining principles. 3. A person who holds a political office. 4. A person skilled in political government or administration; statesman. 5. An expert in politics or political government. 6. A person who seeks to gain power or advancement within an organization in ways that are generally disapproved. -Syn. 4. Politician, statesman refer to one skilled in politics. These terms differ particularly in their connotations; politician is more often derogatory, statesman laudatory. Politician suggests the schemes and devices of one who engages in (esp. small) politics for party ends or his own advantage: a dishonest politician. Statesman suggests the eminent ability, foresight, and unselfish devotion to the interests of his country of one dealing with (esp. important or great) affairs of state: a distinguished statesman.

One practical thing that lexicographers could do is include more informal discussions of the sort given at the end of (18), not only concerning connotations, but various types of meaning criteria.

There has been a trend within linguistics in recent years to investigate how lexical items can be decomposed into component meanings. A classical example is the word "kill" which, it has been suggested, has the meaning of "(directly) cause to become not alive." Such structures can be shown to be necessary for the description of meaning by the way that hedges work when they are used to modify words like "kill." Consider the sentences:

(19) In a sense it was John who killed Mary.

(20) What John did was, in a sense, kill Mary.

In (19) the "in a sense" hedges on the directness of the causation. It would be appropriately used just in case, say, John didn't directly cause Mary's death, though he might be said, indirectly through something he did, to have caused Mary's death. In (20) the hedge modifies "alive." So the second sentence might be used in a case where John didn't literally kill Mary, but, say, where he did something to ruin her career, given that her career was something she held very precious, and that her whole ego depended on. That is, he might have destroyed her professional life.

A similar case to the example in (20) occurs with the word "orphan." An orphan might be defined as an individual, usually a child, whose parents are not alive. Now consider the sentence:

(21) In a sense, John is an orphan.

(21) might be said of someone whose parents were not literally dead but, say, had been in a bad accident and would never recover consciousness though they were literally alive. In this case "in a sense" is hedging on "alive." Similarly, it might hedge on "parents." That is, it might pick out people who were "in a sense" parents, for example, mentors in the business world. So, for instance, a junior executive might be said to have become "an orphan in a sense" if all of his mentors were fired from the company. 
Hedges have only just begun to be investigated, and my guess is that further research will yield considerable insight not only into the way they operate, but also into the semantic structure of lexical items. This is an enterprise in which, I think, linguists and lexicographers can make use of one another's knowledge. It is an area where lexicographers can use their detailed knowledge of words, acquired through the practice of their craft, to make contributions to a linguistic understanding of lexical meaning. And I hope that the use of hedges as a tool for determining types of meaning criteria will lead to an even greater heightening of the lexicographer's art.

\section{Acknowledgment}

The author wishes to thank Herbert Clark for a number of the examples used.

\section{REFERENCES}

1. ZADEH, LoFTr. 1965. Fuzzy sets. Information and control, 8, pp. 338-53.

2. Heider. E. R. 1971. On the internal structure of perceptual and semantic categories. Unpublished mimeo, Psychology Department, University of California, Berkeley, Calif.

3. Lakoff, G. 1972. Hedges. Papers from the eighth regional meeting of the Chicago Linguistics Society. Linguistics Department, University of Chicago, Chicago, Ill.

\section{Discussion}

W. Nelson Francis (Brown University, Providence, R.I.): 1 am delighted myself to learn that there are such things as "fuzzy sets." Back in the fifties when we are all trying to be very rigorous in defining linguistic categories, I was bold enough to say that a class of words like adjectives may be very clear in the center but gets fuzzier and fuzzier as you get out to the periphery. This was a very bad thing to say back in the fifties; you remember that Jim Sledd, in his Short Introduction to English Grammar (1959), said that adjectives are only those things which can take the -er and -est suffixes, and therefore beautiful is no more an adjective than chaos is a noun. I think Jim has changed his views a little since then. I now have a lovely term for what I was talking about-a "fuzzy set."

On the subject of hedges, there is one hedge that I particularly like because it is so contrariwise and must really upset non-native speakers-that is, literally. If you say "John is literally a fish," you mean about the same thing as "he is a regular fish," which means he is not literally a fish at all. I have never looked in any dictionary to see if this meaning of literally is included. It's a real challenge to a lexicographer to say that literally means the opposite of literal. 